\title{
Editorial - New Management and Market Liberalism
}

A common thread in this edition, as it has been for a number of its predecessors, is the issue of organisational adaptation in response to environmental change and uncertainty. Over ten years since the fall of the Berlin wall, post-socialist managers still find themselves searching for the capacities needed to achieve organisational survival in the new liberal economic order. Not only is the attribute of strategic thinking a much sought after competence, but also there is a need overhaul managerial structures in order to expedite a shift from production led mentality towards the satisfaction of customer needs. Despite the apparent diversity of contributions to this edition the imperative of changing organisational purpose can serve to unite them.

Igor Gurkov and Shlomo Maital report on the findings of a large sample survey of attitudes among over 1,400 Russian middle managers and 740 Chief Executive Officers. The authors reveal that it is the younger, middle level managers who tend to possess the capacities most likely to promote organisational success in the new era. The new generation of managers is found to be less autocratic and hierarchical in orientation than technically mindedsuperiors, and embraces the need for conflict resolution and team building skills. According to the authors, a challenge for western organisations is to tap into the skills of this new dynamic layer of managerial talent, possibly through incepting internal ventures.

Brian Kenny casts light upon the hitherto under-researched defence sector in east Europe. The article takes a comparative view of developments across western and eastern Europe, and charts re- organisation of the industry against a back- cloth of broader political change. The thawing of the cold war and the conditional acceptance of the Czech Republic, Hungary and Poland into NATO are identified as significant catalysts. The author concludes, albeit in a qualified fashion, that global competition is leading to consolidation of the European aerospace and defence industries and to potential integration across east and west. These developments imply profound shifts in culture on the part of eastern providers.

Iča Rojšek places a focus upon developments in the management of customer relationships in Slovenia. The results of a survey of fifty manufacturing companies are mapped against broad theoretical insights. It is asserted that the previously assumed interaction between two companies (i.e. customer and supplier) has been an over- simplified notion. Instead the authors point to networks of relationships involving other agencies such as banks, market research agencies and other customers. The article also highlights the significance of engendering high trust relationships between key strategic actors.

Stefan Slavik critically assesses the propensity of Slovakian management to engage in strategic decision making. Drawing upon data from a sample of 
enterprises, and characterising the business environment around these enterprises, it is concluded that the vocabulary of strategic thinking tends to have been adopted at only a formal level. The author concludes, somewhat alarmingly, that if indigenous managers do not gain the will to enforce their own strategies, then multinational corporations will assume this responsibility by incorporating Slovak enterprises into their supply chains.

G. Hollinshead, Bristol Business School 